\title{
The Effect of Solar Irradiance on the Mortality of Phakopsora pachyrhizi Urediniospores
}

S. A. Isard and N. S. Dufault, Department of Plant Pathology, Pennsylvania State University, University Park, USA; M. R. Miles and G. L. Hartman, USDA/ARS, Department of Crop Sciences, University of Illinois, UrbanaChampaign, USA; J. M. Russo, ZedX Inc., Bellefonte, PA, USA; E. D. De Wolf, Department of Plant Pathology, Pennsylvania State University, University Park, USA; and W. Morel, Centro Regional de Investigatión Agrícola, Capitán Miranda, Paraguay

\begin{abstract}
Isard, S. A., Dufault, N. S., Miles, M. R., Hartman, G. L., Russo, J. M., De Wolf, E. D., and Morel, W. 2006. The effect of solar irradiance on the mortality of Phakopsora pachyrhizi urediniospores. Plant Dis. 90:941-945.

Soybean rust, caused by Phakopsora pachyrhizi, may be the most important foliar disease of soybean. Within the last 10 years, the fungus has moved to many new geographical locations via spread of airborne urediniospores. The objective of this study was to determine the relationship between urediniospore viability and exposure to solar radiation. Urediniospores of $P$. pachyrhizi were exposed in Capitán Miranda, Paraguay, to determine the deleterious effects of sunlight. Concomitant total solar $(0.285$ to $2.8 \mu \mathrm{m})$ and ultraviolet $(0.295$ to $0.385 \mu \mathrm{m})$ irradiance measurements were used to predict urediniospore germination. Urediniospores exposed to doses of solar and ultraviolet (UV) radiation $\geq 27.3 \mathrm{MJ} / \mathrm{m}^{2}$ and $\geq 1.2 \mathrm{MJ} / \mathrm{m}^{2}$, respectively, did not germinate. The proportions of urediniospores that germinated, normalized with respect to the germination proportion for unexposed urediniospores from the same collections, were a linear function of solar irradiance $\left(R^{2}=0.83\right)$. UV measurements predicted normalized germination proportions equally well. Results of inoculation experiments with exposed $P$. pachyrhizi urediniospores supported the results of the germination trials, although the effects of moderate levels of irradiance varied. The relationship between urediniospore viability and exposure to solar radiation has been incorporated into the U.S. Department of Agriculture's soybean rust aerobiological model that provides North American soybean growers with decision support for managing soybean rust.
\end{abstract}

Additional keywords: aerobiology, urediniospore dispersal

Soybean rust, caused by Phakopsora pachyrhizi Sydow, is the most serious foliar disease of soybean (Glycine max) worldwide. Substantial economic losses attributed to this plant pathogen have occurred in Asia, Australia, Africa, and South America (12). In 2003, yield losses in Brazil exceeded $6 \%$ of the annual production $(9,18)$. The pathogen has over 95 known alternative hosts from 43 genera of legumes which may serve as reservoirs for the pathogen when soybean is not present (5). Unfortunately, cultivars with resistance to soybean rust are currently unavailable, and foliar fungicides to manage the disease will add significantly to production costs (12).

The urediniospores of $P$. pachyrhizi have demonstrated swift and frequent aerial movement at local, regional, and global scales (8). P. pachyrhizi was initially detected in the United States at the Louisiana

Corresponding author: S. A. Isard
E-mail: sai10@psu.edu

Accepted for publication 8 March 2006.

DOI: 10.1094/PD-90-0941

(C) 2006 The American Phytopathological Society
State University research farm on 6 November 2004 (16,17). Three years earlier, it had appeared for the first time in the Western Hemisphere throughout the Rio Parana region of Paraguay and southern Brazil (12). During subsequent years, soybean rust spread to wherever soybean was planted within South America between $30^{\circ} \mathrm{S}$ latitude and the equator (18). By 2004, the pathogen had reached the soybean production regions in central Argentina and in the Andes Mountains of Colombia (8).

Using the CLIMEX model to predict the effects of climate on soybean rust, Pivonia and Yang (14) indicate that $P$. pachyrhizi will likely survive on soybean and/or alternative hosts year-round in Mexico, the Caribbean Islands, and wherever appropriate hosts are present along the Gulf of Mexico in the United States. The analysis revealed that winters in the central United States are too harsh for year-round $P$. pachyrhizi survival. In these areas, soybean rust epidemics will be dependent on longdistance aerial dispersal of urediniospores from a subtropical source region.

The aerial spread of soybean rust depends on the ability of urediniospores to survive environmental conditions encountered during transport. If urediniospores were dispersed from India to Central Africa, from Africa to South America, and then from South America to North America, they must have the ability to survive in the air for many days, perhaps as long as 2 weeks. Output from an aerobiology transport model suggests that the first rust urediniospores to invade the United States likely arrived from Columbia during September 2004 in association with Hurricane Ivan, which swept across the Caribbean Sea (8). For this event to have occurred, the pathogen would have had to survive the range of temperature, relative humidity, and solar irradiance conditions encountered over a period of 9 to12 days.

The effect of exposure to solar irradiance on the survival of $P$. pachyrhizi urediniospores has not been studied. However, Aylor and colleagues $(3,13,15)$ have examined the effect of temperature, relative humidity, and solar radiation on survival of detached spores of Alternaria solani, Peronospora tabacina, Phytophthora infestans, Uromyces appendiculatus, and Venturia inaequalis. The major finding of these studies was that solar radiation, especially its ultraviolet (UV) component, was the primary cause of mortality during exposure. The objective of this study was to quantify the effect of solar irradiance on the survival of detached $P$. pachyrhizi urediniospores. The evaluation of the effects of solar radiation on urediniospore survival may improve the accuracy of aerobiologybased modeling systems (e.g., USDA Soybean Rust Information System, http://sbrusa.net) and facilitate predictions of $P$. pachyrhizi dispersal to soybean fields in the middle latitudes of North America from overwintering habitats in the subtropics.

\section{MATERIALS AND METHODS}

In this study, germination of $P$. pachyrhizi urediniospores was measured following exposure to varying levels and durations of solar irradiance. Germination of urediniospores was used as an indication of the ability of urediniospores to survive and withstand environmental stress. Inoculation trials were also conducted using urediniospores exposed to different solar irradiances. The trials were carried out on 14 days during February and March 2005 on the Centro Regional de Investigatión 
Agrícola station in Capitán Miranda, Paraguay. All $P$. pachyrhizi urediniospores used in the trials were collected from soybean (var. Conquistan) planted in irrigated plots 10 weeks prior to the start of the trials. The plants were infected naturally by windblown dispersal of urediniospores from neighboring fields.

Spore collection. $P$. pachyrhizi urediniospores were collected in the morning ( 0700 to 0800 local time) of each trial as soon as the dew had evaporated from the soybean leaves. The urediniospores were gently brushed from the underside of the infected leaves onto an aluminum tray for transport to a laboratory, where they were temporarily held in a 10-ml glass vial.

Solar radiation trials. Urediniospores (ca. $200 \mathrm{mg}$ ) were tapped from the vials, brushed through a filter (ca. $40 \mu \mathrm{m}$ ) to remove large particles and disrupt clusters, and deposited onto inverted covers of 100 by $15 \mathrm{~mm}$ plastic petri dishes. The sporeladen covers were separated into three sets. At the start of each trial, urediniospores from one set of covers were transferred to water agar as described below to determine initial germination percentage (germination controls). A second set was placed onto a wire grid platform on a table in the center of a large grass-covered courtyard where they were exposed to the entire sky (except very near the horizon) and protected from strong wind gusts. The wire platform was raised $3 \mathrm{~cm}$ above the table top to allow ventilation under the clear petri dish covers. A third set of treatments was arranged identically to exposure treatments, but the inverted lids with urediniospores were placed on a shelf under the table in full shade (shaded controls). Two lids with urediniospores from each of the second and third sets (exposed and shaded) were removed from the table for processing after varying amounts of time.

Because doses of solar irradiance from single-day exposure trials did not completely inhibit germination, 2-day trials were conducted following published procedures (10). The spore-laden petri dishes were stored at $5^{\circ} \mathrm{C}$ in darkness overnight. Sets of samples were tested for germination before and after storage. There was no statistically significant effect of overnight storage on germination proportion under these conditions.

Total solar radiation $(0.285$ to $2.8 \mu \mathrm{m})$ and ultraviolet radiation (0.295 to 0.385 $\mu \mathrm{m})$ were measured with an Eppley pyranometer (Model 848, Eppley Laboratory Inc., Newport, RI) and an Eppley Total UV radiometer (Model \#6676, Eppley Laboratory), respectively. The radiometers were calibrated by the authors prior to deployment and by Eppley Laboratory upon completion of the measurement program. Air temperature $\left({ }^{\circ} \mathrm{C}\right)$ and relative humidity (\%) were measured using a Vaisala HMP45C (Vaisala, Helsinki, Finland) temperature and relative humidity
(RH) probe. All measurements were made each second, averaged for 1-min intervals, and stored in a Campbell $21 \mathrm{X}$ datalogger (Campbell Scientific, Logan, UT).

Following exposure (sun, shade, or no exposure), the spore-laden covers were placed over $20 \mathrm{~g} /$ liter water agar (Difco Bacto) in 100-mm-diameter plastic petri dishes. The tops were tapped sharply until all urediniospores in the covers were deposited onto the water agar surface. The plates were then incubated in complete darkness for $18 \mathrm{~h}$ at $20^{\circ} \mathrm{C}\left( \pm 2^{\circ} \mathrm{C}\right)(10)$. The germination proportion of the first 100 urediniospores observed on the agar surface using a microscope $(\times 200)$ was recorded for each treatment and control. When no germination was found associated with the first 100 urediniospores, all the urediniospores $(1,000$ to 2,000$)$ on the agar surface were inspected.

Inoculation trials. Urediniospores in petri dish lids were exposed to solar irradiation levels of 10 and $23 \mathrm{MJ} / \mathrm{m}^{2}$, while urediniospores from the same collections were placed in a $10-\mathrm{ml}$ glass vial on the shelf under the table (shaded controls). Environmental conditions were recorded following the methods described above.

After exposure, urediniospores were tapped into glass dishes, then brushed into a $150-\mathrm{ml}$ solution of sterile water and Tween $20(0.1 \%)$. The resulting solutions were hand-mixed and diluted to a density of 5,000 to 20,000 urediniospores $/ \mathrm{ml}$. Urediniospore solutions $(150 \mathrm{ml})$ were misted onto the leaves of 120 greenhousegrown soybean plants (var. Aurora) at growth stage V1. Water was misted onto a set of 120 plants as a control treatment. The soybean plants were placed into a mist chamber $(100 \% \mathrm{RH})$ at $20^{\circ} \mathrm{C}\left( \pm 2^{\circ} \mathrm{C}\right)$ for 16 $\mathrm{h}$ to stimulate infection. The plants were subsequently moved out of the mist chamber onto benches in a rust-free greenhouse. The severity of soybean rust on the plants was evaluated 14 days after each inoculation using a $15 \times$ optical glass binocular magnifier (Donegan Optical Co., Lenexa, $\mathrm{KS}$ ) to count the number of lesions on the first trifoliolate of 40 plants in each treatment. The inoculation trials were done twice during March and April 2005.

Analysis of data. Initial germination proportions varied between 41 and $58 \%$ for the trials conducted with urediniospores collected from the field on different days. Consequently, to compare the results from the trials, the germination proportions for all treatments were normalized with respect to the mean initial germination proportion for their respective trial (germination controls). Relationships between survival of urediniospores and doses of radiation for the exposure trials were calculated by using least squares linear regression analyses; $t$ tests were used to evaluate differences among slope parameters estimated for individual days (4). The Kolmogorov-Smirnov test was used to evaluate differences between the observed distribution of the germination proportion for the control treatments and a normal distribution (11). Differences among treatment means in the inoculation trials were evaluated using ANOVA (SAS Institute, Cary, NC).

\section{RESULTS}

The sky during 15 to 18 February 2005 was exceptionally clear at the field station, while overcast conditions prevailed on 21 and 23 February 2005. The environmental conditions during the 6 days of the radiation exposure trials are shown in Figure 1. Environmental conditions during the 2-day exposure trials conducted during early March are not displayed, but the days were mostly sunny with temperature and humidity conditions within the same range as those for the measurement days in February.

The parameters associated with the linear relationships between total solar and UV irradiance and germination proportion, normalized with respect to the germination proportion for unexposed urediniospores (germination controls) from the same collections, were evaluated for individual days (Table 1). Differences among the slopes of the regression lines for individual days were not statistically significant ( $\alpha=$ 0.1 ), so were pooled for all trials. The proportion of germinating urediniospores in the 37 shaded control treatments for the experiments conducted over the 2-week period were normally distributed with mean and standard deviations of 0.483 and 0.037 , respectively (Fig. 2). Germination in the shaded control treatments was not impacted by exposure durations up to $8 \mathrm{~h}$ (Fig. 3). Air temperatures during these trials were typically in the upper 30 s to mid 40s, while relative humidity values generally ranged between 25 and $50 \%$ (Fig. 1).

The proportion of the exposed urediniospores that germinated, normalized with respect to the germination proportion for unexposed urediniospores (germination controls) from the same collections, was plotted against total solar irradiance using the data from all days (Fig. 4). A linear relationship fit using least squares regression yielded an $R^{2}$ value of 0.83 . Urediniospores exposed to $\geq 27.3 \mathrm{MJ} / \mathrm{m}^{2}$ did not germinate. A similar analysis used to estimate the normalized germination proportion $(Y)$ as a function of UV radiation exposure $(X)$ gave $Y=1.0011-0.6724 X$. The proportion of variation in normalized germination accounted for by UV irradiances $\left(R^{2}=0.83\right)$ was the same as that for total solar irradiance. Urediniospores exposed to a UV irradiance $\geq 1.2 \mathrm{MJ} / \mathrm{m}^{2}$ did not germinate.

Results of the inoculation experiments using urediniospores exposed to moderate and high treatments of total solar radiation $\left(10\right.$ and $23 \mathrm{MJ} / \mathrm{m}^{2}$ ) are displayed in Figure 
5. Differences in the mean number of pustules per trifoliolate for the no exposure and moderate exposure treatments were not statistically significant but were greater than the mean for the high exposure treatment in the first experiment. All three treatments were statistically different from one another in the second experiment. There was no apparent reason for the difference in the moderate treatments between experiments. Averaging the results for both experiments, the mean numbers of pustules per trifoliolate for the moderate and high exposure treatments as a proportion of the controls were 0.82 and 0.29 , respectively. Germination proportions estimated from the linear relationship presented in Figure 4 for the same exposure levels are 0.71 and 0.32 .

\section{DISCUSSION}

The spread of plant pathogens through the air depends on the ability of disseminules to withstand the conditions they encounter during movement. Over the past decade, urediniospores of $P$. pachyrhizi have survived frequent long distance transport, moving from Asia into Africa, then to South America, and most recently into North America. This study demon- strates that soybean rust urediniospores are sensitive to exposure to solar radiation, which can reduce their viability, and consequently that the movement of soybean rust urediniospores on continental and intercontinental scales of thousands of kilometers must occur under cloud cover.

The proportion of $P$. pachyrhizi urediniospores that germinate decreased with increasing exposure to solar radiation. The results of the inoculation experiments support the findings of the germination trials.
Urediniospores exposed to total solar radiation doses $\geq 27.3 \mathrm{MJ} / \mathrm{m}^{2}$ did not germinate. The fraction of a cohort of urediniospores surviving exposure to a given dose of solar radiation $\left(E_{f}\right)$ in an aerobiology model is often expressed as:

$E_{f}=e^{-I I I^{*}}$

where $I$ is the solar irradiance $\left(\mathrm{MJ} / \mathrm{m}^{2}\right)$ and $I^{*}$ is a critical dose $\left(\mathrm{MJ} / \mathrm{m}^{2}\right)$ that kills a fraction $1-1 / e$ of the spores $(1,2,8)$. A total solar irradiance of approximately 21

Table 1. Coefficients for linear relationships between solar and UV irradiances and the proportion of urediniospore germination of Phakopsora pachyrhizi

\begin{tabular}{|c|c|c|c|c|c|c|c|}
\hline \multirow[b]{2}{*}{ Date $^{\mathbf{a}}$} & \multirow[b]{2}{*}{$n$} & \multicolumn{3}{|c|}{ Germination vs. total solar irradiance } & \multicolumn{3}{|c|}{ Germination vs. UV irradiance } \\
\hline & & $\mathbf{b}_{0}{ }^{\mathbf{b}}$ & $\mathbf{b}_{1}$ & $R^{2}$ & $\mathbf{b}_{\mathbf{0}}$ & $\mathbf{b}_{1}{ }^{\mathbf{b}}$ & $R^{2}$ \\
\hline 15 Feb 05 & 16 & 0.994 & -0.029 & 0.88 & 0.983 & -0.771 & 0.89 \\
\hline 16 Feb 05 & 16 & 1.042 & -0.025 & 0.85 & 1.037 & -0.693 & 0.84 \\
\hline 17 Feb 05 & 20 & 0.912 & -0.030 & 0.94 & 0.900 & -0.850 & 0.94 \\
\hline 18 Feb 05 & 20 & 0.991 & -0.027 & 0.90 & 0.972 & -0.802 & 0.90 \\
\hline $21 \mathrm{Feb} 05$ & 14 & 1.136 & -0.031 & 0.85 & 1.131 & -0.845 & 0.86 \\
\hline 23 Feb 05 & 6 & 0.864 & -0.022 & 0.49 & 0.875 & -0.586 & 0.49 \\
\hline
\end{tabular}

${ }^{a}$ Effect of solar and UV irradiances were evaluated on six dates and the results of each date evaluated independently.

${ }^{\mathrm{b}} \mathrm{b}_{0}$ and $\mathrm{b}_{1}$ are coefficients in the linear equation $Y=\mathrm{b}_{0}+\mathrm{b}_{1} X$ where $X$ is solar or UV irradiance $\left(\mathrm{MJ} / \mathrm{m}^{2}\right)$ and $Y$ is normalized germination proportion. $R^{2}$ is the coefficient of determination, and $n$ is the number of exposed plates. Comparisons among coefficient values for individual days are not statistically significant at $\alpha=0.1$.
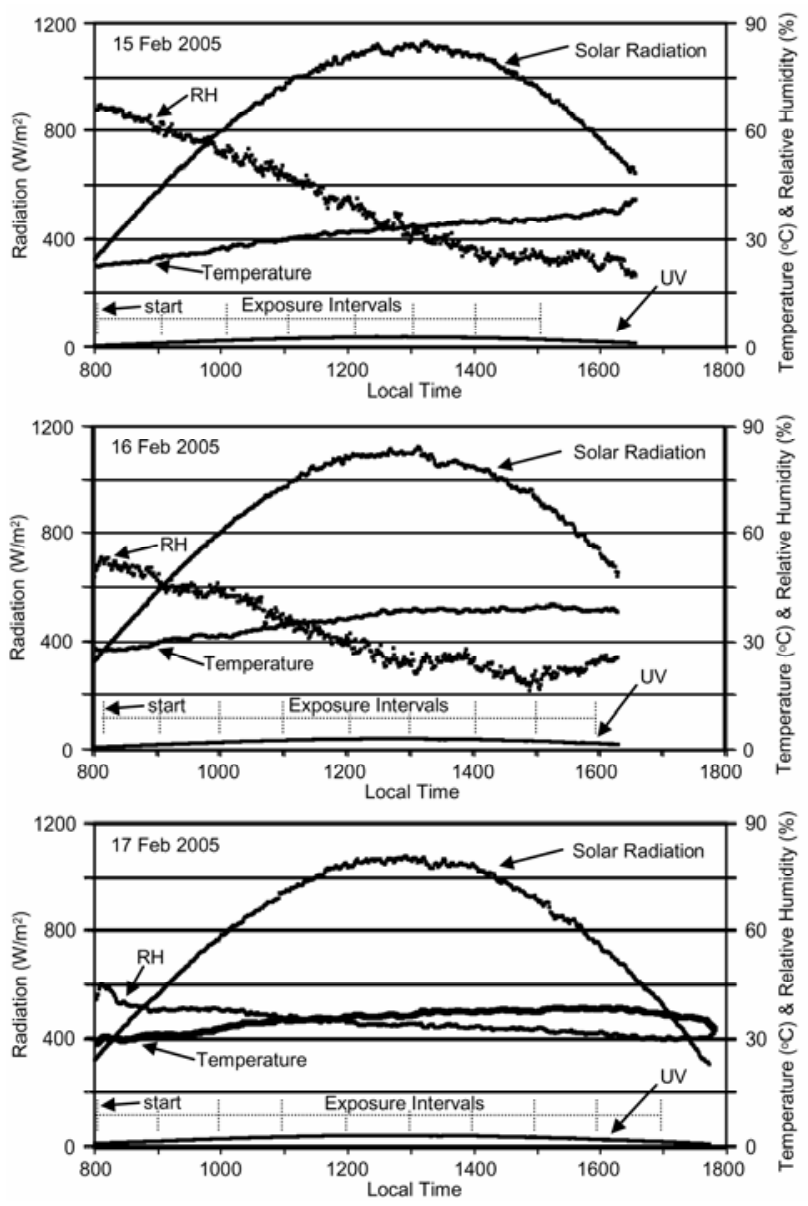
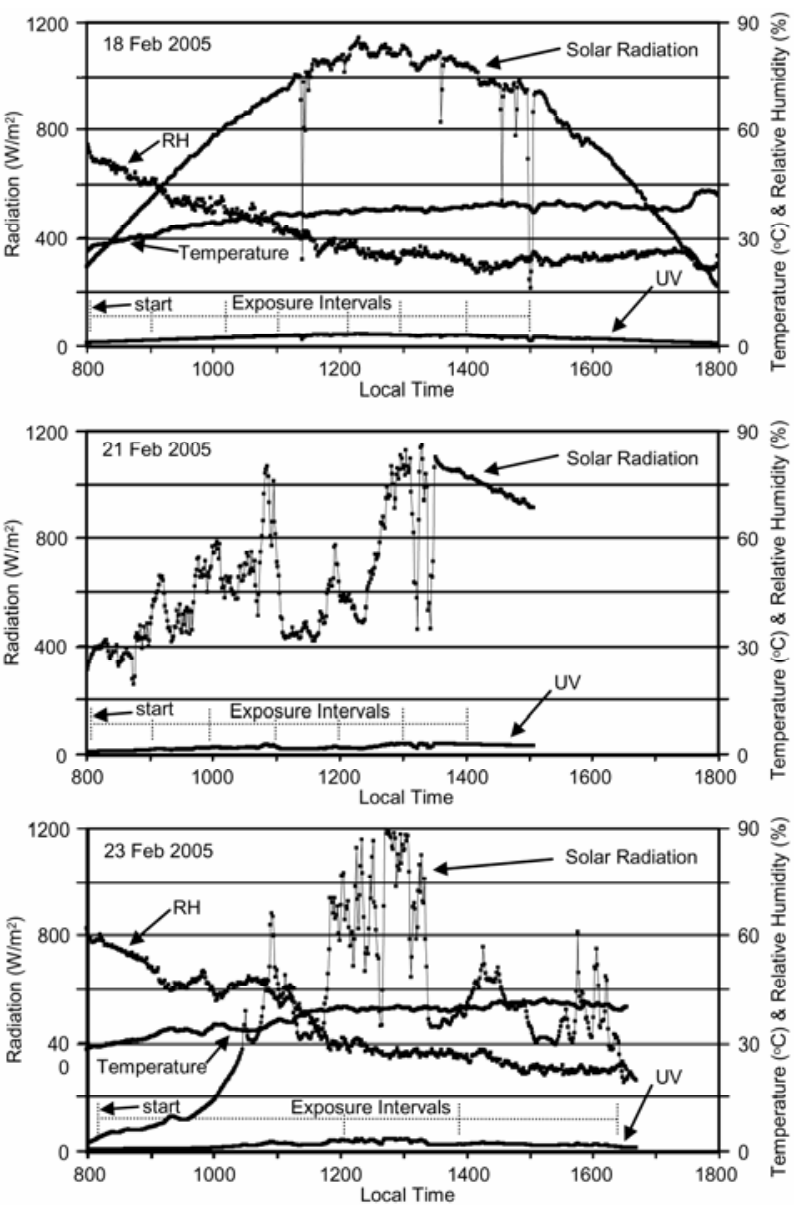

Fig. 1. Total solar and ultraviolet radiation, air temperature, and relative humidity measurements for days when Phakopsora pachyrhizi spores exposure trials were conducted in Capitán Miranda, Paraguay. Scales for total solar and UV radiation data are on the left axis, while air temperature and relative humidity scales are on the right. Air temperature and relative humidity were not recorded on 21 February 2005. Start and termination times for each exposure are presented in the lower portion of the plot for each day. 
$\mathrm{MJ} / \mathrm{m}^{2}$ resulted in a mortality of $63.2 \%$ of the exposed $P$. pachyrhizi urediniospore population. The critical doses of total solar irradiance for A. solani, Peronospora tabacina, Phytophthora infestans, U. appendiculatus, and $V$. inaequalis spores are 35 , $2.4,0.9,25$, and $21 \mathrm{MJ} / \mathrm{m}^{2}$, respectively (2). The linear form of the relationship between germination and total solar radiation exposure found in this study differs from the exponential decay form proposed by Aylor $(1,2)$ for spores exposed to sunlight. This difference has important implications to aerobiological forecasts of risk from pathogens such as soybean rust where inoculum can be transported long distances over multiple days, and new loci of infection in deposition areas may be initiated by small numbers of viable urediniospores.

We can evaluate differences in estimates of urediniospore survivorship from the linear and exponential models using a hypothetical situation in which soybean rust urediniospores are blown $1,300 \mathrm{~km}$ over a 100-h period (e.g., at the $850-\mathrm{mb}$ level with an average wind speed of ca. 13 $\mathrm{m} / \mathrm{s}$ ) from a source along the Gulf of Mexico to a soybean field in the central United States where they are deposited by precipitation. It is plausible that the urediniospores making this journey during the summer months under overcast sky and mostly clear conditions would be exposed to solar radiation doses of approximately 12.5 and $50 \mathrm{MJ} / \mathrm{m}^{2}$, respectively. Using the exponential decay model (equation 1), 55 and $9 \%$ of the viable urediniospores that left the Gulf Coast source region would be viable at deposition in the central United States for the overcast and mostly clear sky scenarios, respectively. In contrast, the linear model predicts that the percentages of viable urediniospores at deposition would be 62 and $0 \%$ for the same scenarios.

Marchetti et al. (10) reported germination proportions for urediniospores of $P$. pachyrhizi strains from Australia, Taiwan, Indonesia, and India as a function of incubation temperature and duration in darkness. We followed their methods using an incubation temperature of $20^{\circ} \mathrm{C}$ and $18 \mathrm{~h}$

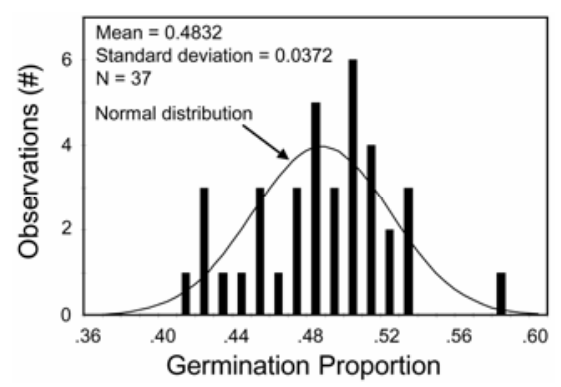

Fig. 2. Distribution of observations of germination proportion for exposure control treatments. The null hypothesis that there is no difference between observed and normal distributions could not be rejected at $\alpha=0.2$ using the Kolmogorov-Smirnov test. of darkness because it resulted in high germination proportions. The mean urediniospore germination proportion for the control treatments in our study was 0.48 , similar to values reported by Marchetti et al. (10) for the isolates from Australia, Taiwan, and Indonesia, but less than the germination proportions reported for the Indian strain. Higher germination proportions (0.52 to 0.62 ) for $P$. pachyrhizi urediniospores from infections on greenhousegrown soybean plants has been observed (Reid, M. R. Miles, and G. L. Hartman, personal communication). It was our experience in Paraguay that the germination proportions for field collections of urediniospores from exposed leaves in the upper soybean canopy were generally low, leading us to speculate that urediniospores in pustules on plants may also be impacted by radiation exposure. Germination did not appear to be impacted by the ranges of air temperatures and relative humidity levels typically experienced in the area. To enhance the magnitude and consistency of germination proportions for treatments

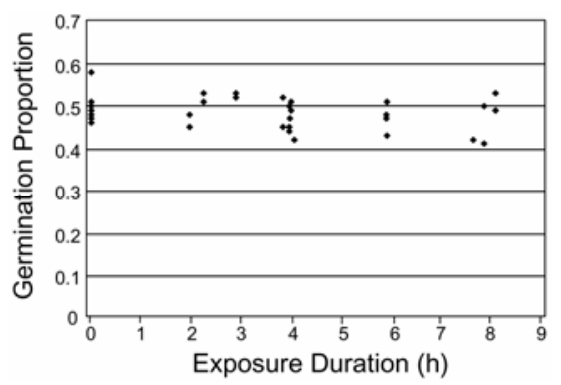

Fig. 3. Relationship between germination proportion and duration of exposure for the 31 shaded control treatments placed on a shelf under the table. Temperature and relative humidity conditions measured on the shelf during the exposures are depicted in Figure 1. among experiments (i.e., the low standard deviation among control treatments), all the urediniospores for this study were collected early in the morning from leaves in the lower soybean canopy.

It is well known that fungal spores are particularly sensitive to the UV wavelengths of solar radiation, especially those between 0.25 and $0.27 \mu \mathrm{m}(6,15)$. However, these wavelengths are practically absent from the solar irradiance received at the earth's surface (7). We found in this study that measurements of total solar

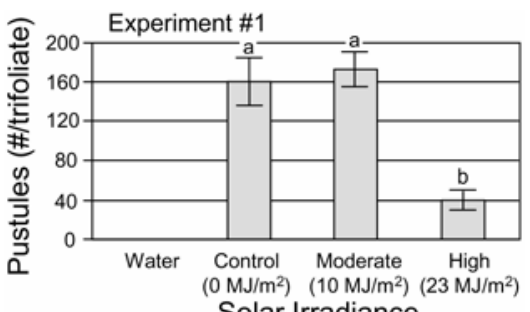

Solar Irradiance

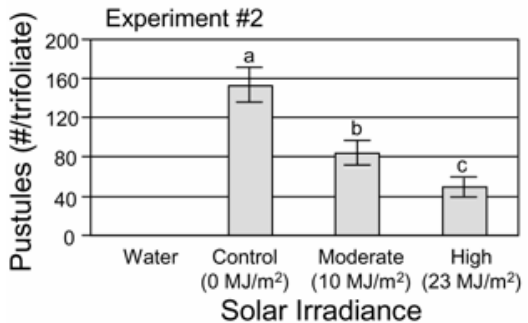

Fig. 5. Mean numbers of pustules on the trifoliolate leaves on soybean plants inoculated with water or urediniospores from treatments with no exposure, moderate exposure, and high exposure to solar radiation. All the pustules on the first trifoliolate of 40 plants in each treatment were counted under a $15 \times$ optical glass binocular magnifier. Bars depict the standard error of the mean. Means with the same letter in each experiment are not statistically significant $(\alpha=$ $0.01)$.

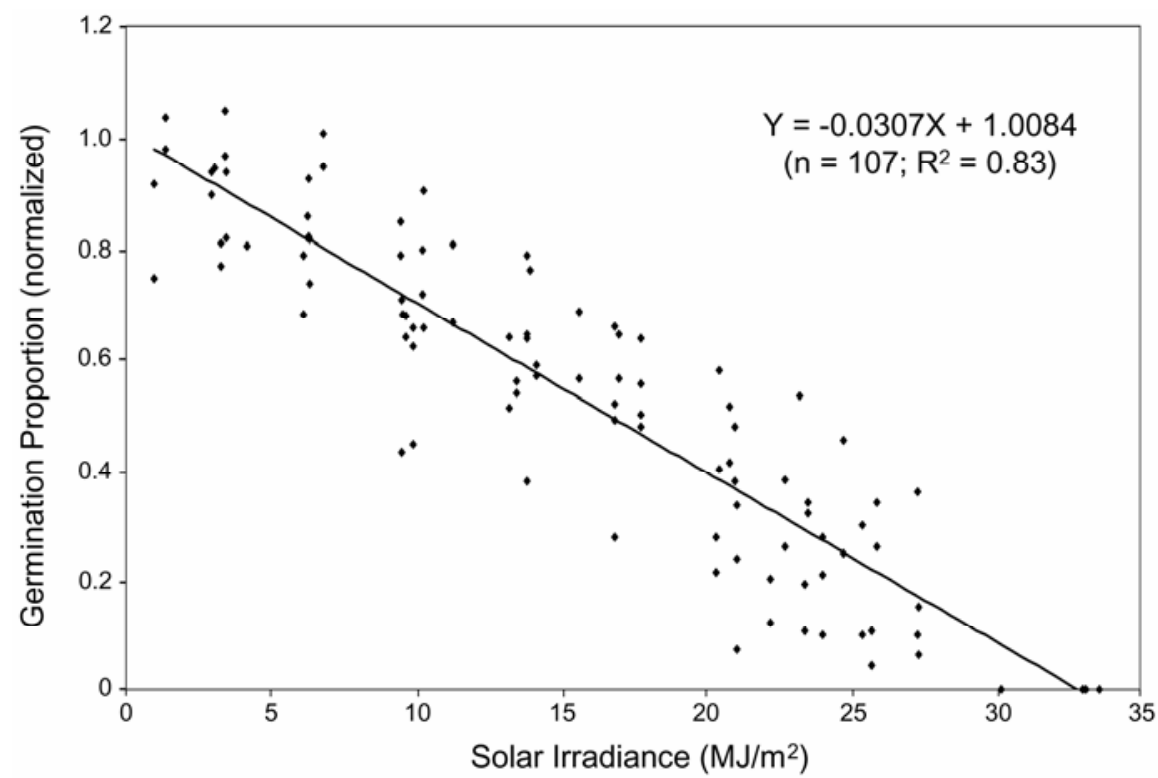

Fig. 4. Relationship between total solar irradiance and the normalized germination proportions of exposed Phakopsora pachyrhizi urediniospores. 
irradiance ( 0.285 to $2.8 \mu \mathrm{m})$ were as good a predictor of germination as UV measurements $(0.295$ to $0.385 \mu \mathrm{m})$. As a result, and due to the greater availability of total solar than UV irradiance measurements worldwide, the parameters of the linear relationship between germination and solar irradiance have been incorporated into the U.S. Department of Agriculture's soybean rust aerobiological model that currently forecasts the risk from the spread of soybean rust throughout North America.

\section{ACKNOWLEDGMENTS}

This research was funded by grants from the USDA Cooperative States Research, Education and Extension Service National Research Initiative Animal and Plant Biosecurity grant program and Pennsylvania State University. We thank Todd A. Steinlage and Tristan A. Mueller for their assistance with the experiments.

\section{LITERATURE CITED}

1. Aylor, D. E. 1986. A framework for examining the inter-regional aerial transport of fungal spores. Agric. For. Meteorol. 38:263-288.

2. Aylor, D. E. 1999. Biophysical scaling and the passive dispersal of fungus spores: Relationship to integrated pest management strategies. Agric. For. Meteorol. 97:275-292.
3. Bashi, E., and Aylor, D. E. 1983. Survival of detached sporangia of Peronospora destructor and Peronospora tabacina. Phytopathology 73:1135-1139.

4. Box, G. E. P., Hunter, W. G., and Hunter, J. S. 1987. Statistics for Experimenters. John Wiley \& Sons, New York.

5. Bromfield, K. R. 1984. Soybean Rust, Monograph, No. 11. American Phytopathological Society, St. Paul, MN.

6. Caesar, A. J., and Pearson, R. C. 1983. Environmental factors affecting survival of ascospores of Sclerotinia sclerotiorum. Phytopathology 73:1024-1030.

7. Iqbal, M. 1983. An Introduction to Solar Radiation. Academic Press, New York.

8. Isard, S. A., Gage, S. H., Comtois, P., and Russo, J. M. 2005. Principles of the atmospheric pathway for invasive species applied to soybean rust. Bioscience 55:851-862.

9. Livingston, M., Johansson, R., Daberkow, S., Roberts, M., Ash, M., and Breneman, V. 2004. Economic and Policy Implications of windborne entry of Asian soybean rust into the United States. Electronic Outlook Report. U.S. Dep. Agric. Econ. Res. Serv., OCS-04D-02.

10. Marchetti, M. A., Melching, J. S., and Bromfield, K. R. 1976. The effects of temperature and dew period on germination and infection by uredospores of Phakopsora pachyrhizi. Phytopathology 66:461-463.

11. Massey, F. J., Jr. 1951. The KolmogorovSmirnov test for goodness of fit. Am. Stat.
Assoc. J. 46:68-78.

12. Miles, M. R., Frederick, R. D., and Hartman, G. L. 2003. Soybean rust: Is the U.S. soybean crop at risk? Online publication. APS Feature Story 06/2003. American Phytopathological Society, St. Paul, MN.

13. Mizubuti, E. S. G., Aylor, D. E., and Fry, W. E. 2000. Survival of Phytophthora infestans sporangia exposed to solar radiation. Phytopathology 90:78-84.

14. Pivonia, S., and Yang, X. B. 2004. Assessment of the potential year-round establishment of soybean rust throughout the world. Plant Dis. 88:523-529.

15. Rotem, J., Wooding, B., and Aylor, D. E. 1985. The role of solar radiation, especially ultraviolet, in the mortality of fungal sores. Phytopathology 75:510-514.

16. Schneider, R. W., Hollier, C. A., Whitam, H. K., Palm, M. E., McKemy, J. M., Hernandez, J. R., Levy, L., and DeVries-Paterson, R. 2005. First report of soybean rust caused by Phakopsora pachyrhizi in the continental United States. Plant Dis. 89:774.

17. Stokstad, E. 2004. Plant pathologists gear up for battle with dread fungus. Science 306:1672-1673.

18. Yorinori, J. T., Paiva, W. M., Frederick, R. D., Costamilan, L. M., Bertagnolli, P. F., Hartman, G. E., Godoy, C. V., and Nunes, J., Jr. 2005. Epidemics of soybean rust (Phakopsora pachyrhizi) in Brazil and Paraguay from 2001 to 2003. Plant Dis. 89:675-677. 